\title{
Effect of whitening toothpastes on microhardness and surface roughness of Bulkfill resins.
}

\section{Bruna S. Strini, Joyce F. M. de Lima, Josué J. A. Pierote, Flávio H. B. Aguiar.}

\begin{abstract}
Due to the recent development of Bulkfill resins, it remains necessary to know the effects of whitening toothpastes on their surface properties. For this reason, the aim of this research was to evaluate the effect of whitening toothpastes on microhardness and surface roughness of Bulkfill resins (Opus Bulk Fill APS - FGM and Filtek Bulk Fill - 3M ESPE) after simulated mechanical brushing.
\end{abstract}

Key words: Composite Resins, Surface Properties, Dentifrices.

\section{Introduction}

In the past years, the use of whitening toothpastes is increasing as a consequence of esthetic demand. However, studies have shown that the greater the whitening capacity of the toothpaste, the grater the damage to the oral cavity. Considering their chemical nature, the restorations present in the oral cavity are more susceptible to modifications caused by these toothpastes. Many studies have evaluated the effect of this type of toothpaste on the surface properties of conventional resins, but little is known about their effects on Bulkfill resins.

\section{Results and Discussion}

The methods were made as the image below:

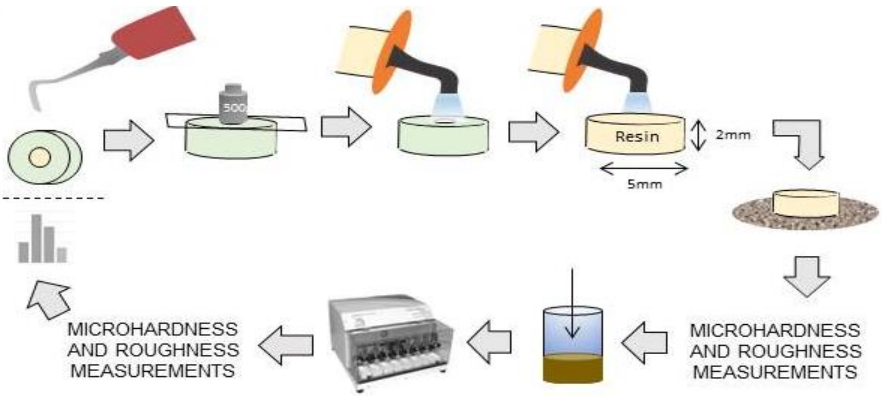

The quantitative data was submitted to two-way ANOVA with repeated measures in time followed by Tukey's test for multiples comparisons with the program SPSS 21 (IBM, Chicago), considering $\alpha=0.05$.

\section{- Microhardness:}

The results showed that the final measurements were statistically higher in comparison with the initial, independent of the type of resin and toothpaste used (Table 1).

\section{- Surface roughness:}

The results showed that the final measurements were statistically higher in comparison with the initial, independent of the resin and toothpaste used. In the initial time there was no statistical difference between the toothpastes, independent of the resin. The resins without mecanichal brushing showed the highest final results in comparison with the resins with Colgate Luminous White and Sensodyne True White. Colgate total 12 was statistically similar to all other groups, independent of the resin (Table 2).
Table 1. Mean (standard deviation) of microhardness (Knoop) in function of the composite resin and toothpaste over time.

\begin{tabular}{lccc}
\hline \multirow{2}{*}{ Resin } & \multirow{2}{*}{ Toothpaste } & \multicolumn{2}{c}{ Time } \\
\cline { 3 - 4 } & & Initial & Final \\
\hline Filtek & Without mecanichal brushing & $56,20(11,97) \mathrm{Ab}$ & $74,55(6,93) \mathrm{Ba}$ \\
& Colgate total 12 & $55,66(9,04) \mathrm{Ab}$ & $85,50(7,97) \mathrm{Aa}$ \\
& Colgate Luminous White & $48,37(6,55) \mathrm{Bb}$ & $78,17(7,27) \mathrm{Ba}$ \\
& Sensodyne True White & $56,90(4,80) \mathrm{Ab}$ & $75,47(9,38) \mathrm{Ba}$ \\
\hline Opus & Without mecanichal brushing & $52,66(7,28) \mathrm{Ab}$ & $68,18(4,79) \mathrm{Ba}$ \\
Bulk- & Colgate total 12 & $47,45(6,43) \mathrm{Ab}$ & $71,16(12,19) \mathrm{ABa}$ \\
Fill & Colgate Luminous White & $51,01(7,31) \mathrm{Ab}$ & $78,29(8,45) \mathrm{Aa}$ \\
& Sensodyne True White & $51,57(7,11) \mathrm{Ab}$ & $65,61(11,16) \mathrm{Ba}$ \\
\hline Filtek & Without mecanichal brushing & $57,25(9,16) \mathrm{Ab}$ & $75,80(5,74) \mathrm{Aa}$ \\
Bulk- & $\quad$ Colgate total 12 & $54,70(9,40) \mathrm{Ab}$ & $79,32(5,72) \mathrm{Aa}$ \\
Fill & Colgate Luminous White & $59,63(6,18) \mathrm{Ab}$ & $75,41(9,49) \mathrm{Aa}$ \\
& Sensodyne True White & $56,65(6,61) \mathrm{Ab}$ & $80,18(7,96) \mathrm{Aa}$ \\
\hline
\end{tabular}

Table 2. Mean (standard deviation) of roughness in function of the composite resin and toothpaste over time.

\begin{tabular}{lccc}
\hline \multirow{2}{*}{ Resin } & \multirow{2}{*}{ Toothpaste } & \multicolumn{2}{c}{ Time } \\
\cline { 3 - 4 } & & Initial & Final \\
\hline Filtek & Without mecanichal brushing & $56,20(11,97) \mathrm{Ab}$ & $74,55(6,93) \mathrm{Ba}$ \\
& Colgate total 12 & $55,66(9,04) \mathrm{Ab}$ & $85,50(7,97) \mathrm{Aa}$ \\
& Colgate Luminous White & $48,37(6,55) \mathrm{Bb}$ & $78,17(7,27) \mathrm{Ba}$ \\
& Sensodyne True White & $56,90(4,80) \mathrm{Ab}$ & $75,47(9,38) \mathrm{Ba}$ \\
\hline Opus & Without mecanichal brushing & $52,66(7,28) \mathrm{Ab}$ & $68,18(4,79) \mathrm{Ba}$ \\
Bulk- & Colgate total 12 & $47,45(6,43) \mathrm{Ab}$ & $71,16(12,19) \mathrm{ABa}$ \\
Fill & Colgate Luminous White & $51,01(7,31) \mathrm{Ab}$ & $78,29(8,45) \mathrm{Aa}$ \\
& Sensodyne True White & $51,57(7,11) \mathrm{Ab}$ & $65,61(11,16) \mathrm{Ba}$ \\
\hline Filtek & Without mecanichal brushing & $57,25(9,16) \mathrm{Ab}$ & $75,80(5,74) \mathrm{Aa}$ \\
Bulk- & $\quad$ Colgate total 12 & $54,70(9,40) \mathrm{Ab}$ & $79,32(5,72) \mathrm{Aa}$ \\
Fill & Colgate Luminous White & $59,63(6,18) \mathrm{Ab}$ & $75,41(9,49) \mathrm{Aa}$ \\
& Sensodyne True White & $56,65(6,61) \mathrm{Ab}$ & $80,18(7,96) \mathrm{Aa}$ \\
\hline
\end{tabular}

$p<0,05$

Vertical upper case letters shows the differences between the toothpastes in each time and resin.

Horizontal lower case letters shows the comparison of times in each resin and toothpaste.

Symbols show the differences between the resins at the same conditions for time and toothpastes.

\section{Conclusions}

It can be concluded that the microhardness and surface roughness of bulk fill resins composite after simulated mecanichal brushing are subject to change, independent of the toothpaste and the resin composite used.

\section{Acknowledgement}

This work was financially supported by PIBIC/Unicamp.

\footnotetext{
1 Joiner A. Whitening toothpastes: A review of the literature. J Dent. 2010;38(SUPPL. 2):17-24.

${ }^{2}$ Tauböck T, Thomas A. Bulk-fill resin composites: An update. Swiss Dent J. 2016;126:812-3.

${ }^{3}$ Roopa KB, Basappa N, Prabhakar AR, Raju OS, Lamba G. Effect of whitening dentifrice on microhardness, colour stability and surface roughness of aesthetic restorative materials. J Clin Diagnostic Res. 2016;10(3):ZC06-ZC11.
} 